\title{
سيكولوجيا الشكل في اعمال جواد سليم
}

\section{م.د. لؤي رصيم داود \\ كلية الفنـوز الجميلة / جامعة القادسية فئة}

\section{Abstract}

The present paper is concerned with " The psychology of form in the works of the Iraqi painter Jawad Saleem, It is an attempt to show the psychological dimensions behind the formal aspects and structures of Saleem's is paintings. The paper falls into five chapters . chapter one present the problem of the research, its significance and the approach of the study as well as identifying the terms of psychology and form in terms of modern painting. The second chapter deals with the concept of psychology between stimulus and response ; the concept of form as a visual factor ; an introductory note to Iraqi modern painting; and finally Jawad saleems life and career. As for chapter three, it is concerned with an analysis of three selected works for Jawad saleem through a descriptive - analytical approach, with reference to both form and content. Chapter four presents the results and their discussion. Finally chapter five sums up references,

notes, charts, appendixes, and abstract in English .

\section{خالهة البمث}

ان طبيعة الرسم العر اقي المعاصر تتطلب الكثير من الدراسـة والتمحيص للعو امل المؤثرة في اسـاليبه الفنية وخو اصـها و البحث عن هويته المميزة واهم الفنانين المؤثرين به ، في بحثنا الموسوم ( سيكولوجيا الثكل في اعمال جو اد سليم ) نحاول الكثف عن جانب مهم في لوحات هذا الفنان الا وهو الجانب السيكولوجي في نركيبة الشكل وما يحيل اليه من قيم تعبيرية ، لذا فإن الباحث ومن خلال اعتماده المنهج الوصفي التحليلي لغرض رصد الخو اص والمميزات السيكولوجية التي تتخذ من بنية النكل وتركييته منفذاً لها في لوحات جو اد سليم . من خلال الفصل الاول قام الباحث بتحديد مشكلة البحث و أهميتها والمنهج المتبع ، وتحديد مصطلح السيكولوجيا والشكل، بمـا ينو افت ومفـاهيم الرسم وغايـة البحث ـ وفي الفصل الثاني في مبحثه الاول تم التعريف بمفهوم السبكولوجيا مـا ببين المؤثر و الاستجابة ، وفي المبحث الثاني تم التطرق لمعنى الثكل و علاقته بأدر اكنا كمؤثر بصري ودلالته في العمل الفني ، وفي المبحث الثالث تم تحقيق مدخل للرسم العر اقي المعاصر بما يتو افق وحاجة الفترة الزمنية التي تتو افق مع مجريات البحث في المبحث الرابع تم تحديد الاطار المرجعي للفنان جواد سليم والمؤثرات البيئية ورؤيته ودر استه الفنية ، في الفصل الثالث قام الباحث بتحليل (r) ثلاث عينات قصدية للفنان جواد سليم باعتماد آلية عمل واحد لكل ثلاث سنوات كعينة قصدية لرصد المتغير ات التي ممكن ان تواجه مجريات البحث ولقصر عمر الفنان الفني ، وفق معايير محددة ومنهج وصفي تحليلي في تحليل الثكل والمضمون.في الفصل الرابع تم عرض النتائج ومناقتتها، وفي الفصل الخامس عرض الباحث الاستتاجات ومن ثم الهوامش والمصادر و الملاحق والمصـورات واخير ا ملخص البحث باللغة الانكليزية .

\section{النصل الأول-}

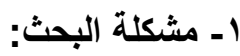

إنَ طبيعة العمل الفني الذي يمثل مؤثراً بصـرياً في مدركات المتلقي نرى فيـه الكثير مـن الخواص التي تتطلب

در استها بشكل متخصص ودقيق للتحقق من قيمة العمل الفني وما هيته ، سواء ا كان على مستوى الفن العـالمي أو الفن العر اقي المعاصر الذي يعُد وليد تجارب فنية حديثة هي مزيج ما بين مؤثرات خارجية وداخلية يجب در اسـة خو اصـها، 
التي قد تأخذ جو انب ليست فنية و لا جمالية صرفة ، بل سيكولوجية لأهمينها البالغـة في فهم تركيبة العمل الفني الذبي

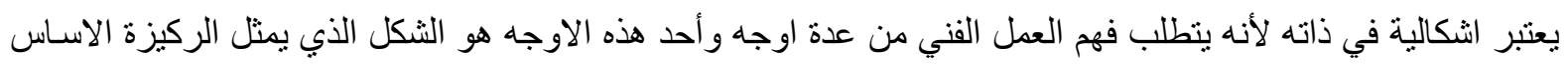

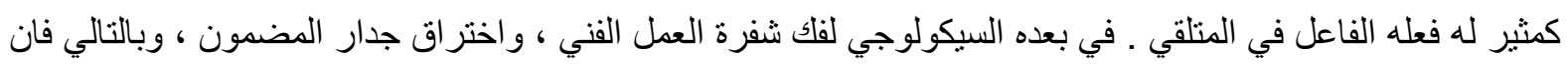

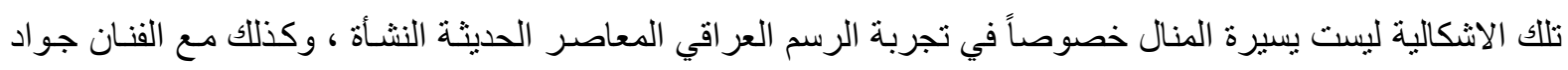

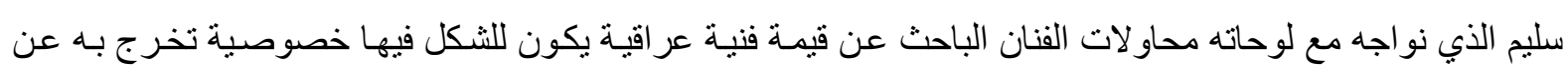

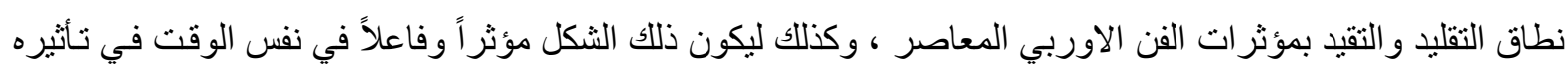

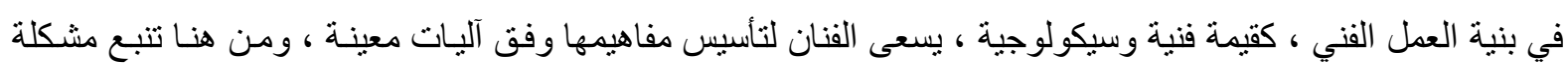

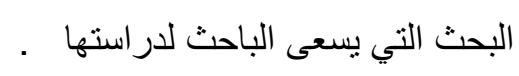

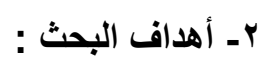

أـ تحديد المؤثرات السيكولوجية للشكل في لوحات جواد سليم

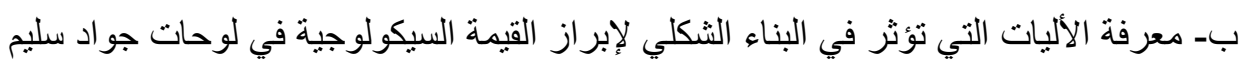
r- أهمية البحث والحاجة اليه:

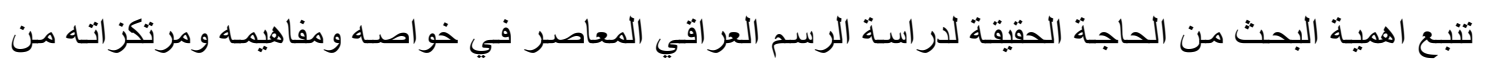

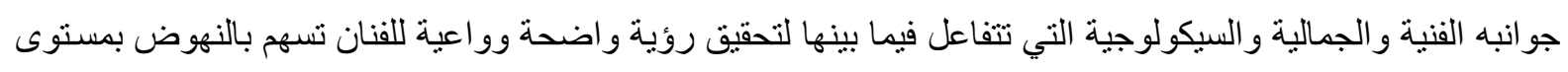

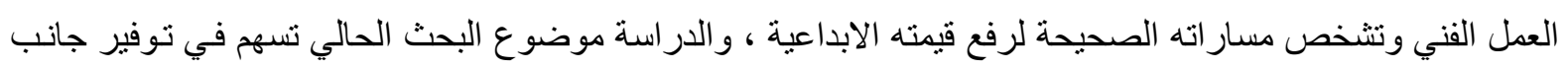

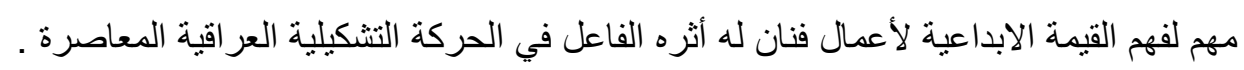
عـ حدود البحث: تتمثل حدود البحث بتحليل اللوحات النشكيلية الخاصة في مرحلة الخمسينات من حياة الفنان جو اد سليم

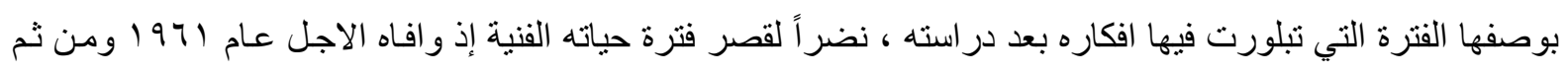

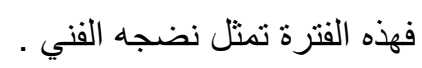
هـ منهج البحث: يعتمد الباحث المنهج الوصفي التحليلي باختيار عينات قصدية من لوحات الفنان بوصفه يتمتع بوحدة اسلوبية وبما يتناسب وغاية البحث

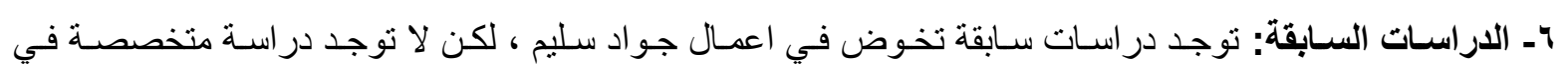

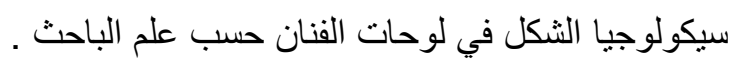

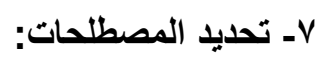
سيكولوجيا: ((ان مجال السيكولوجيا هو المعرفة الحسية ، فهي لا تعرف من الفكر سوى الضوء الذي يسلطه على الذي

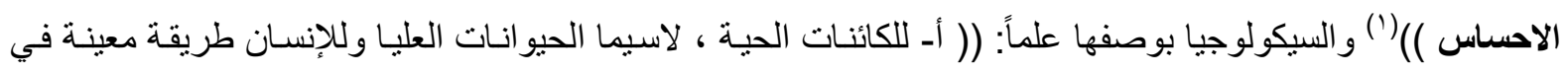

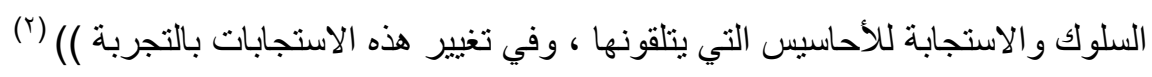

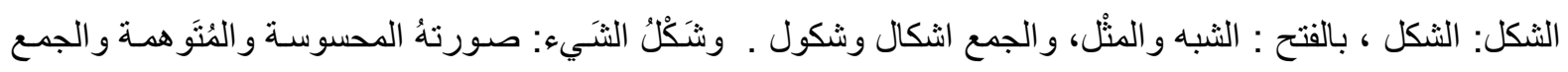

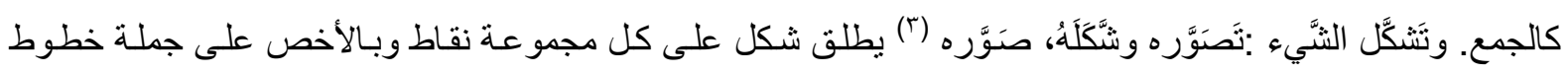

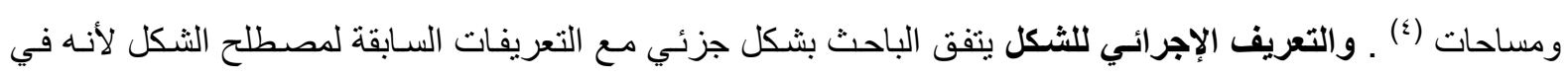

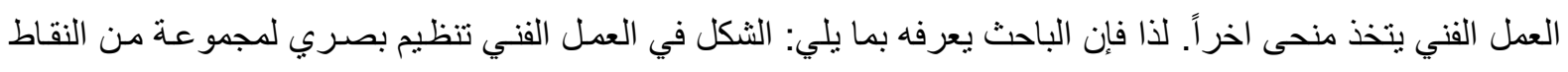

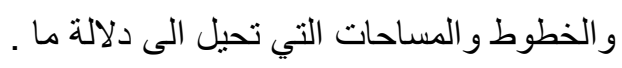




\section{النصل الثاني : الاطار النظري}

المبحث الاول : مفهوم السيكولوجيا : المباي

السيكولوجيا بطبيعتها علم له خصوصيته في دراسة السلوك و الظو اهر النفسية لدى الانسـان ، عبر النتساط القائم

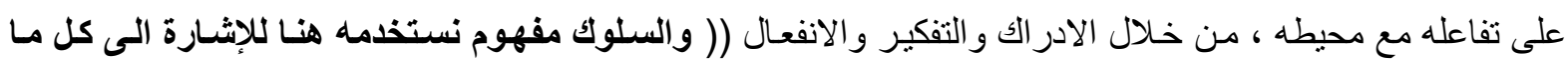

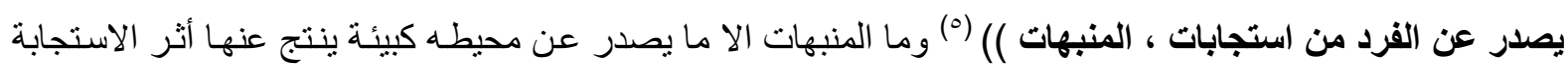

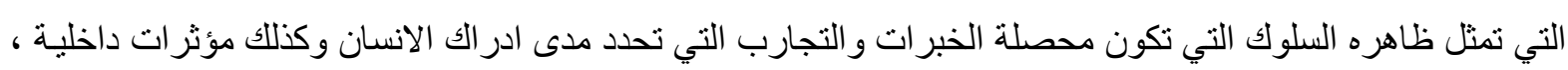

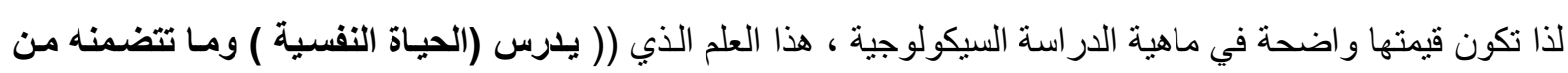

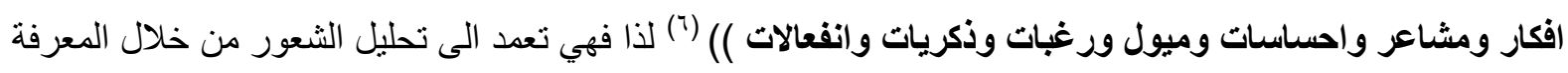

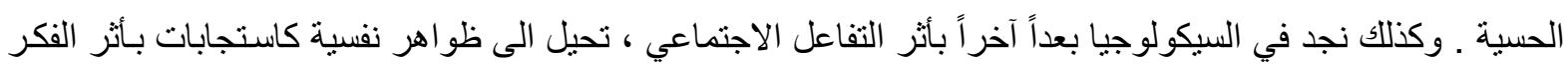

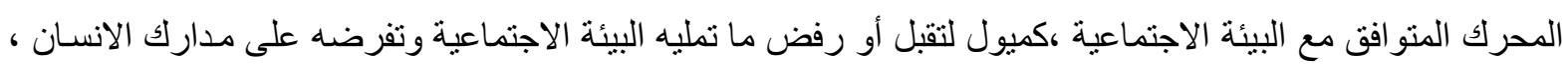

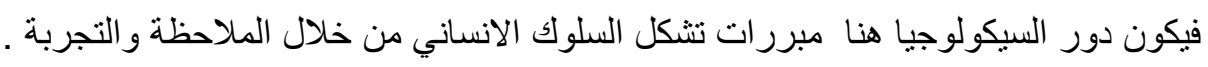

$$
\text { المبحث الثاني : معنى الثكل }
$$

كل شيء يحيط بنا له شكل نبصره كمؤثر في ادر اكنا الحسي ، اذا كان شكلاً طبيعياً أو بـأثر فعل كائن مـا ، فـإن

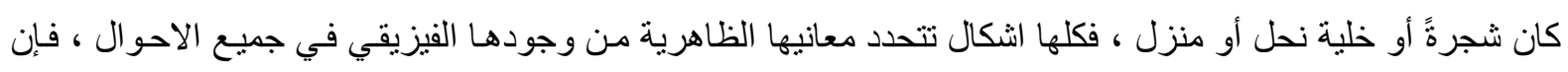

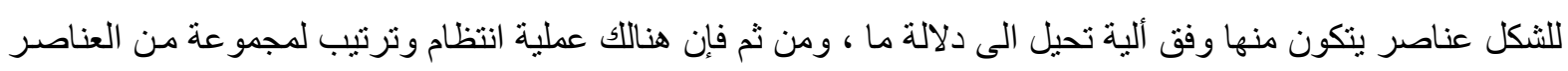

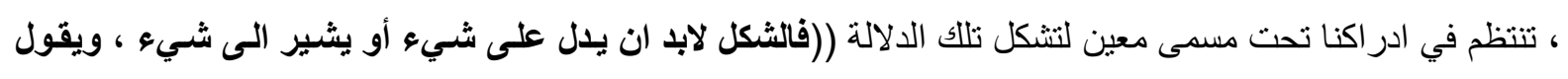

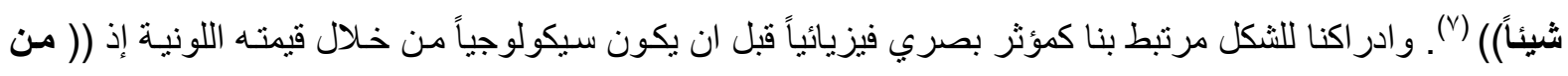

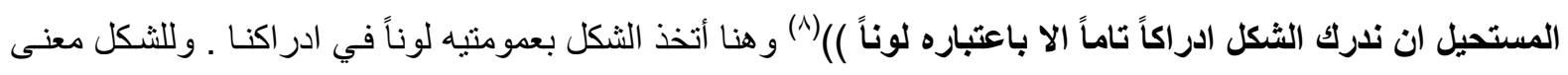

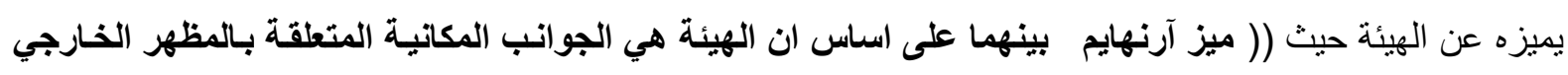

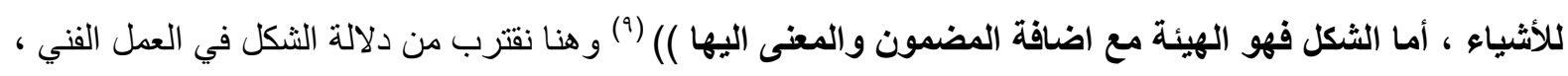

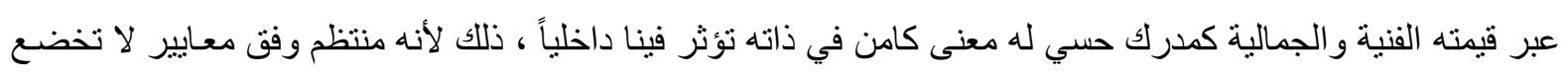

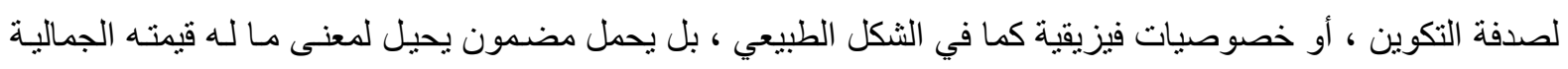
و التعبيرية حيث (( في الفنون البصرية تلكك التجمعات والتضافرات من الخطوط والالوان أو حبكة الخطوط والالوان

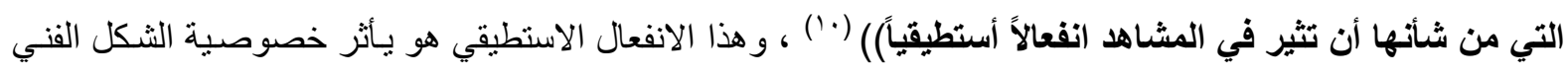

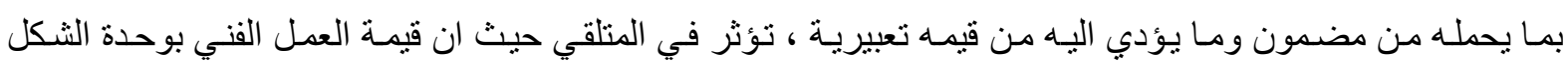

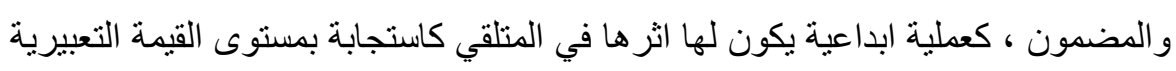

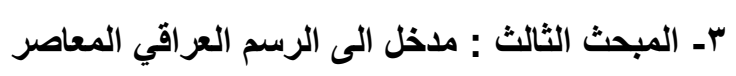
يعرف عن الرسم العر اقي المعاصـر في بدايـة القرن العشـرين انـه لـم يكن لـه مـا يميزه لأنـه محدد برسـوم

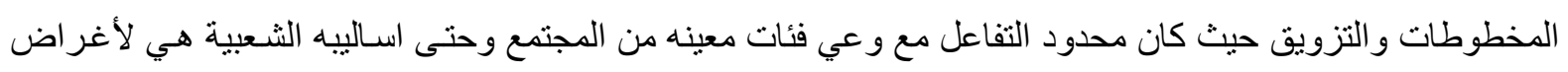

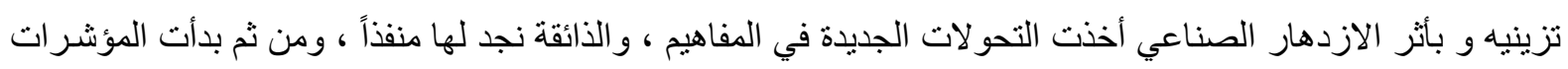

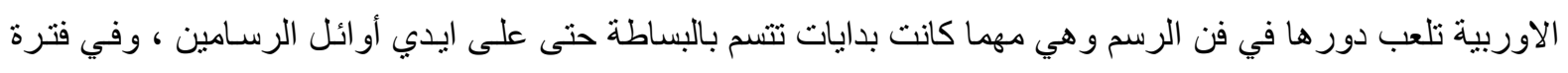

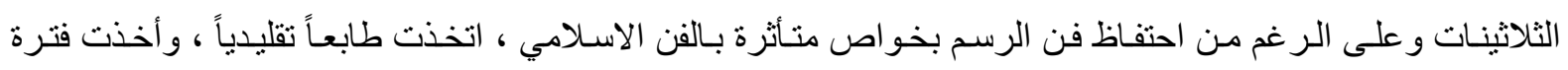

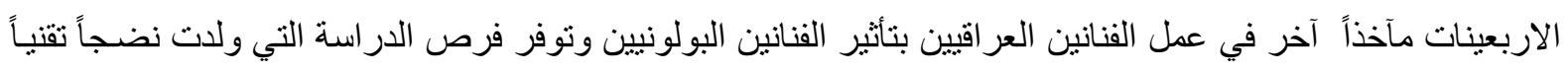


وتولد مفاهيم ورؤى جديدة ما بين و عي الفنان و انتمائهد ومـا تأثثر بـه ، ومـا أن بدأت فترة الخمسينات حتى بدأت مرحلة

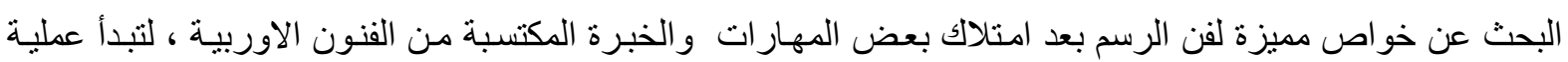

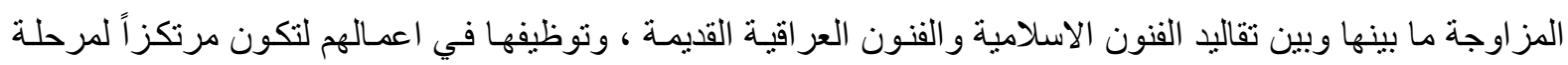

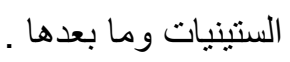

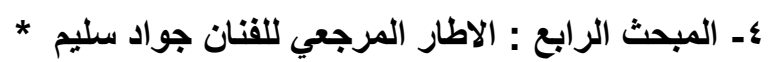

لغرض فهم ماهيـة اي عمل فني يجب در اسـة الاسس و السياقات التي تمخضت عن عن و لادتـه حيث ان النظرة

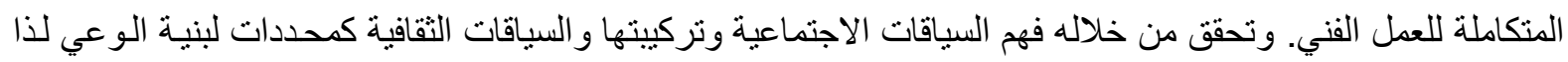

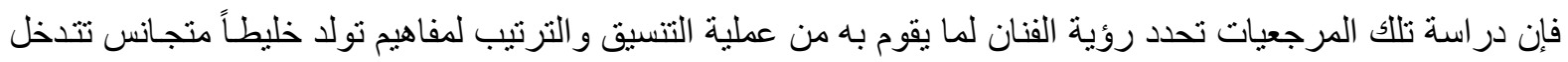
فيه تلك السياقات ، بالإضافة الى النفسية ولميثولوجييه لتشكل بمجموعها وعي الفنان إذ نرى ان مرجعية الفنان جو اد

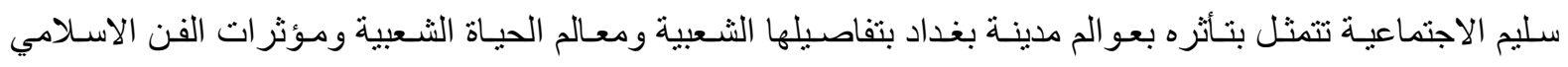

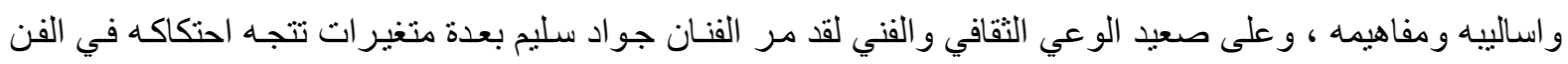
العالمي بعد ارساله للار اسة في أوربا مع فنانين من جيله ، اصبحت لديه فرصة للاكتثاف و والمقارنة ، بعد امتلاكه الثقافة الفنية المطلوبة التي أدت به الى فهم محيطه ، حيث بدأت بوادر التحول في الوعي والاتجاه نحو البحث عن منافذ جديدة

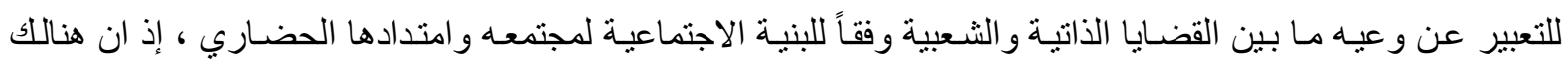
ظروفاً اجتماعية واسعة التأثير في المجتمعات في ذلك الوقت ، ومنها المجتمع العر اقي تحت ضنغط الحرب وابن و انعكاساتها

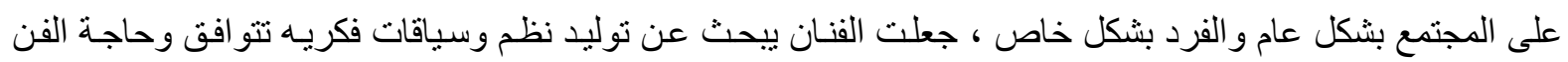

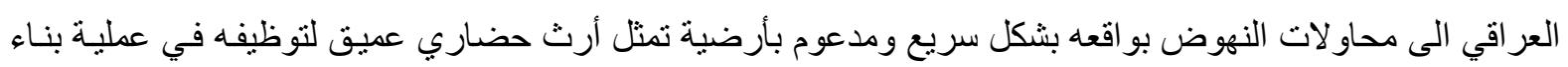

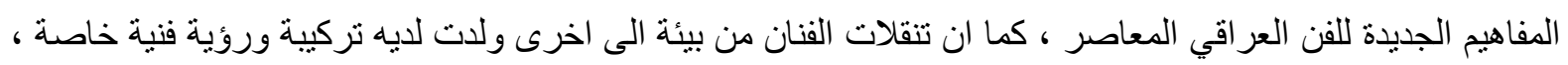
وكذلك المؤثرات الميثولوجية التي نمت في ذهن الفنان جواد سليم لها أثرهـا الفاعل في وعيـه الفني حيث تنبـه الفنـان لخو اص الفن العر اقي القديم برموزه التي تتضح لدينا في الكثير من الرموز الثعبية المتو ارثة ، وهي اعمق جذور النشاط

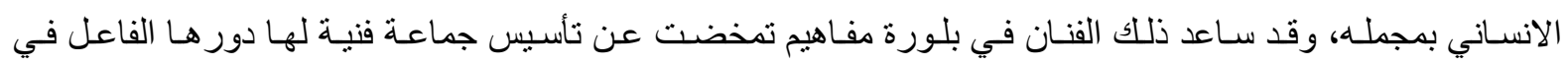
المتغير ات التي طر أت على الفن العر اقي فيما بعد وكانت هذه الجماعة هي (جماعة بغداد للفن الحديث) إذ ذ صميم الفكرة

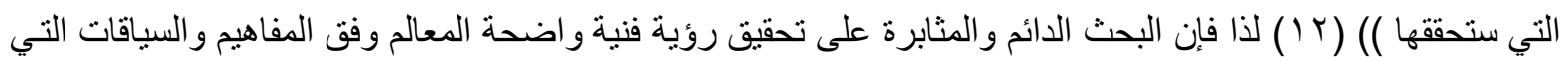
يرنكز عليها في وعيه و عمله نوضح لنا خصوصية مرجعيات الفنان.

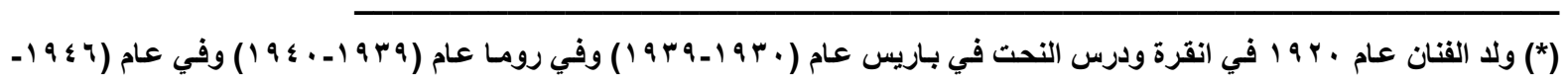

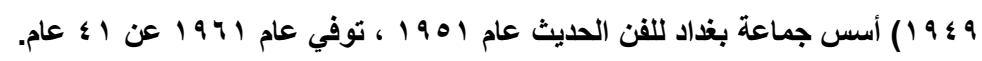

الفصل الثالث: إجراءات البمث في هذا الفصل سيتم تحديد الاجر اءات المتمثلة في تحديد مجتمع البحث، و العينـة القصدية في اعمال الفنان جو اد سليم وكما يلي: أـ قام الباحث بتحديد مجتمع البحث، ممثلاً بجميع اللوحات الفنية التي قام الفنان برسمها في مرحلة الخمسينات لعمره الفني القصير وكونها الفترة التي تبلورت فيها افكاره .

ب- مبررات اختيار العينة القصدية: لقد تم اختيار العينات القصدية وفق المبررات التالية: 
ا - بما ان الفنان جواد سليم يتمتع بوحدة اسلوبية واضحة ولعمره الفني القصير إثر وفاته المبكرة يمكن اعتبار اعماله

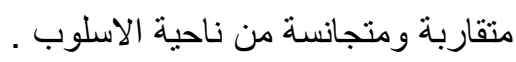

r- اختيار ثنلاث عينـات (عينة) لكل ثنلاث سنوات من مرحلة الخمسينات لتغطية اي متغير ولتحقيق مصداقية التحليل

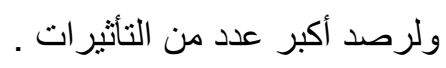

ج- طريقة التحليل : يعتمد الباحث المنهج الوصفي التحليلي لتحقيق مصداقية وفهم عميق للعمل الفني بأثر معطيات

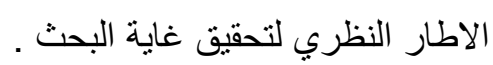

دـ اداة التحليل : ان اداة التحليل التي سيعتمدها الباحث هي عملية تحليل ( الثنكل والمضمون ) لفهم سيكولوجيا الثنكل

في لوحات الفنان

التصائ

شكل رقم (1) بغداديات به 19 1 : موضوع هذا البحث رجل وامرأة في يوم زفافهما ، وفق اعراف وتقاليد بيئة اجتماعية

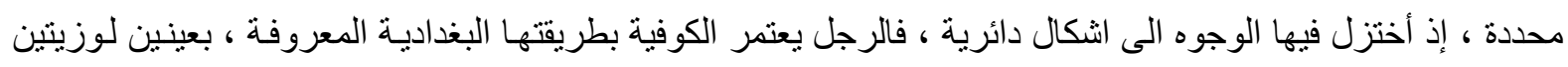

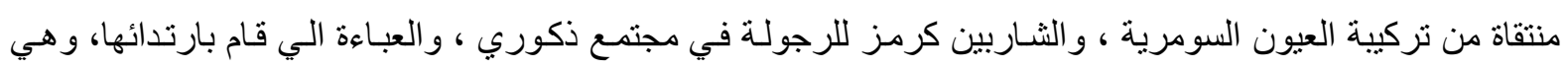

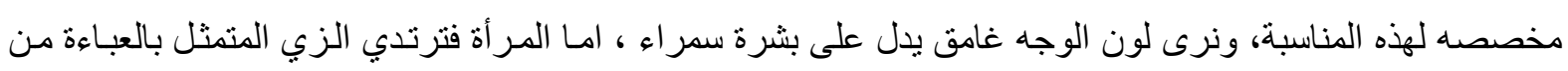
جهة اليسار بلون اسود يمتد على شكل خط في جهة اليمين ليحتوي شكل مُناظر للعباءة في جهة اليسار ، و وهو بدلئل

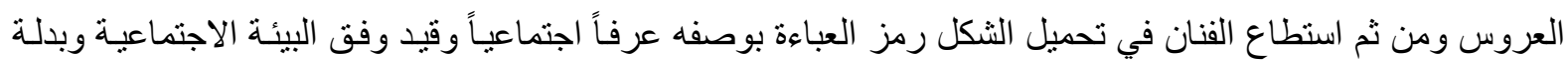

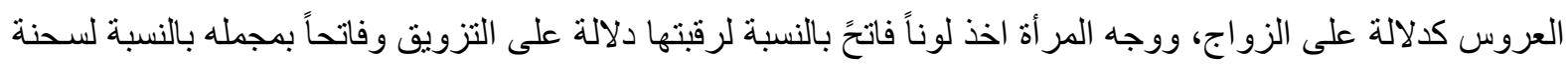

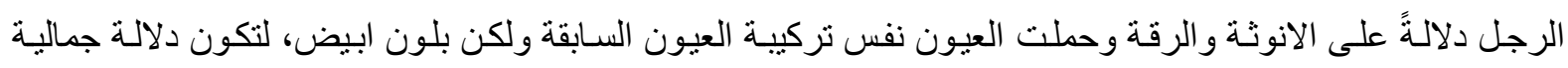

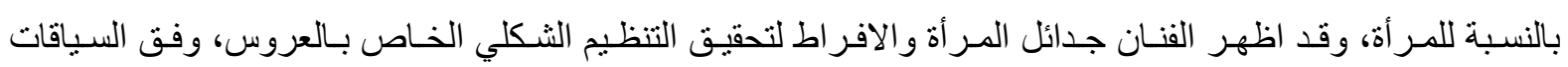
الاجتماعية والسيكولوجية الخاصة بنلك المناسبة، ونرى في هذا العمل التناظر في الاشكال الانسانية لكن التكامل بين

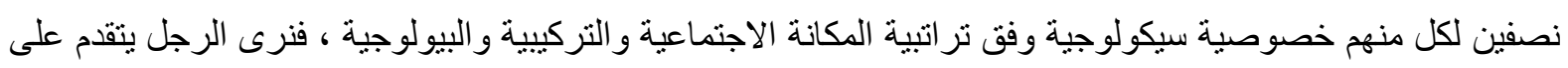
المر أة لتأخذ أكتاف الرجل مقدمة اللوحة لتوحي ان المرأة تقف خلف الرجل وفق المعايير الاجتماعية واخذت خلفية اللوحة اشكال أقو اس هلالية مختزلة مشتقة من مفاهيم الفن الاسلامي أنشاره الى الفرح وبساطته.

عندما تنظر الى القيم و الاشـار ات والعو امل المؤثرة في البناء الثنكلي نرى ان الفنان أقام عمله هذا وفق ثنائية

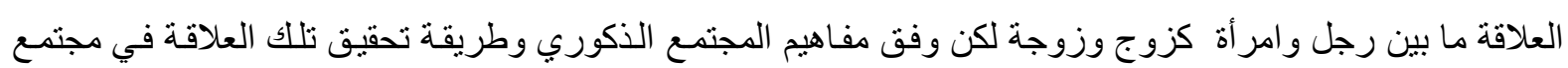

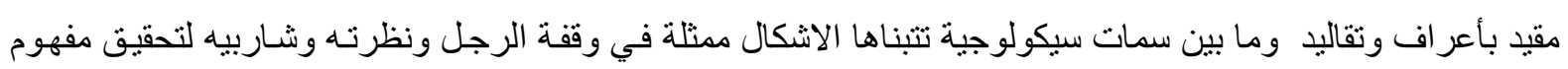

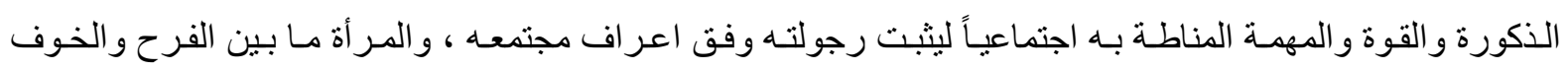

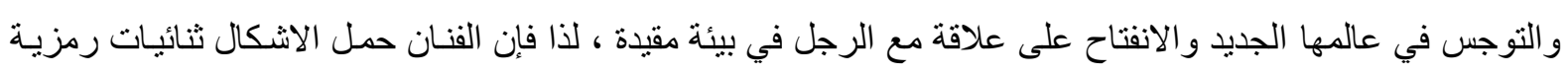

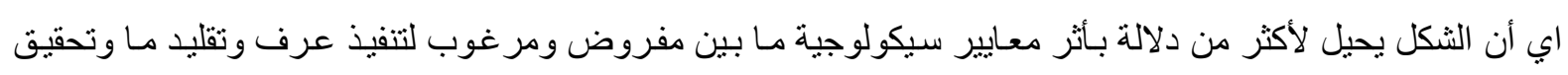

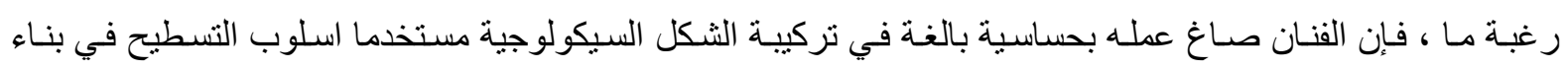

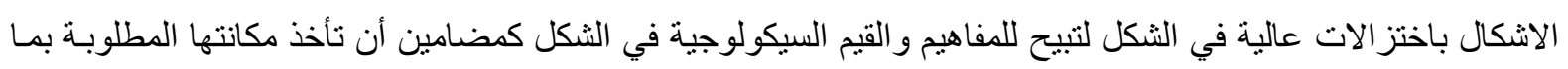
تحققه الاشكال من قيم تعبيرية .

شكل رقم (r) موسيقى الثـارع 1907 : نرى في هذا العمل الذي يمثل موضوعاً شعبياً أن الفنان قام بجعل خلفيـة اللوحة تحمل اشكال زخرفية وتفاصيل لبيئة بغدادية ، حيث منتصف اللوحة اخذ شكل قوس كبير بمثل ثلاثة ارباع مساحة 
اللوحة . ليستقر في وسطه موسيقي يحمل بوق في يده. ويؤدي معزوفة شعبية بوجه جانبي يمثل نصف دائرة وعين امامية وشاربه التقليدي ، و أحيط ر أسه بكوفية على شكل أقو اس ويرتدي عباءة استخدم الفنان في تركيبها الاقو اس ويتجهـ ببوقه النحاسي الاصفر باتجاه بسار اللوحة نحو الموسيقيين الآخرين، وللخلف منه امر أة بزيها العربي الذي يمثل بيئة

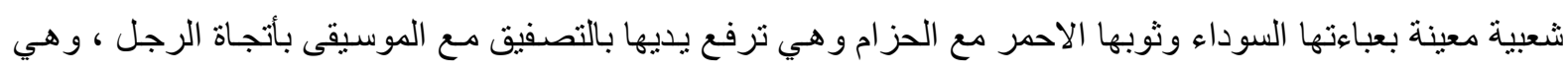

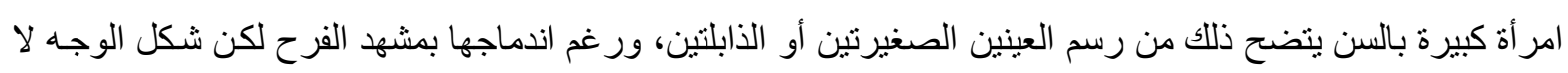

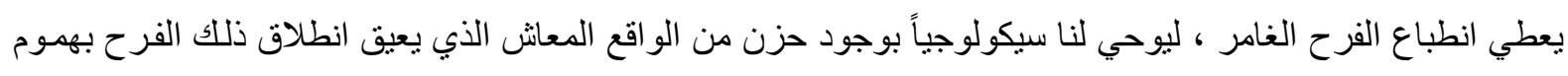

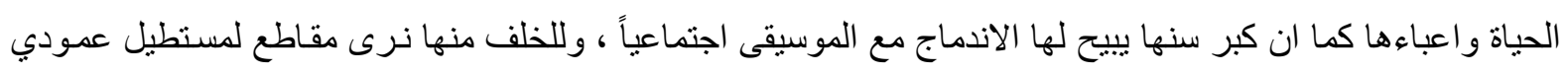

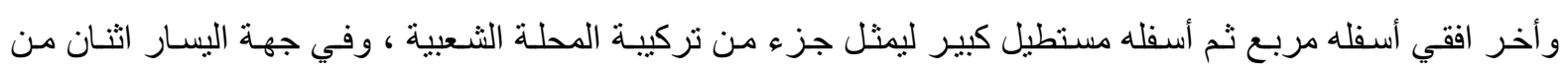
الموسقيين يتجهون نحو الموسيقي الاول ، ويشكلان تناظر اً في توزيع الاشخاص حيث الاول طبال بوجه دائري و وعيون

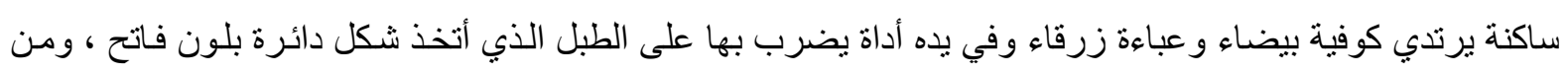

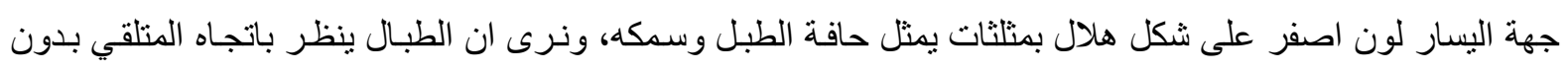
دلالة على الفرح بل مجرد إداء وظيفي ، أي وجود في صخب الموسيقى ووجود في عالم آخر يعكس واقع آخر ، ونرى لئل

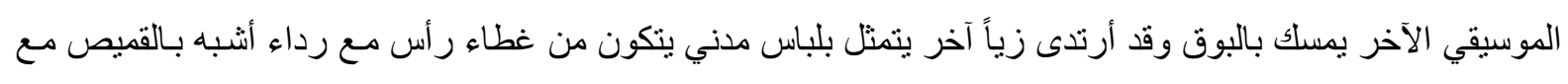

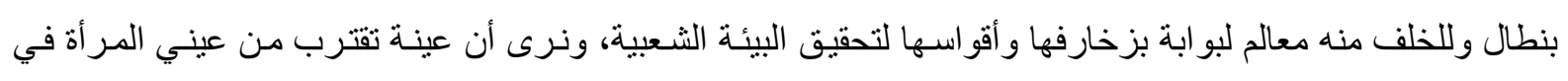

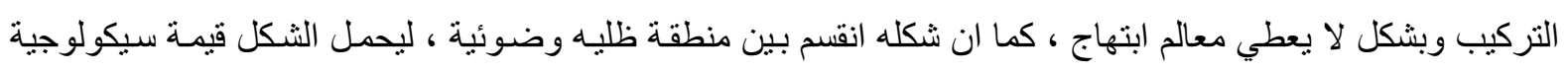

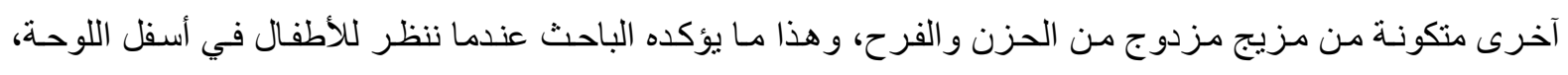

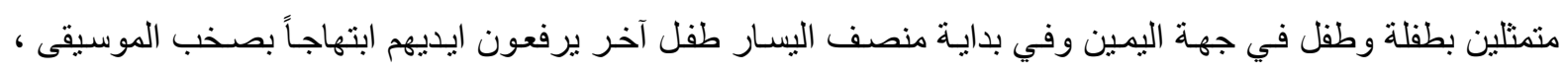

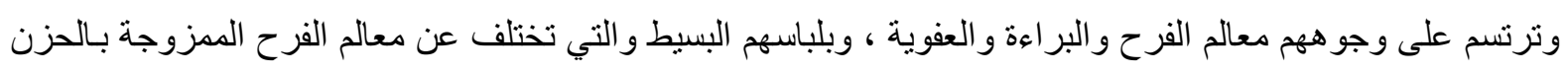

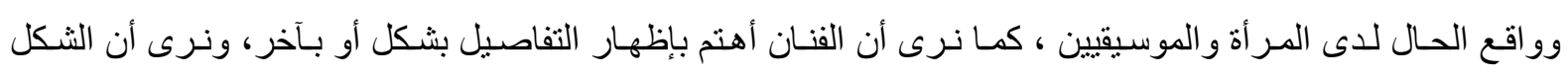

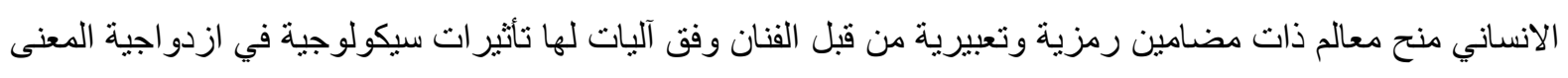

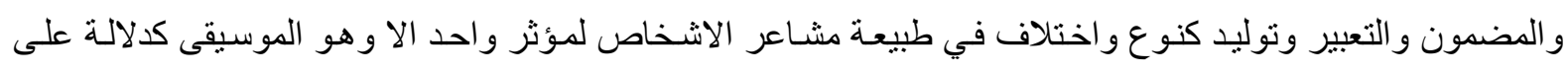

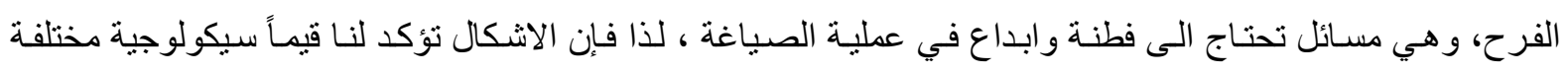

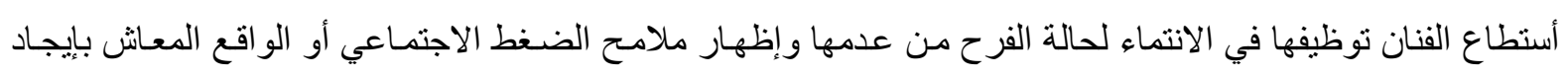

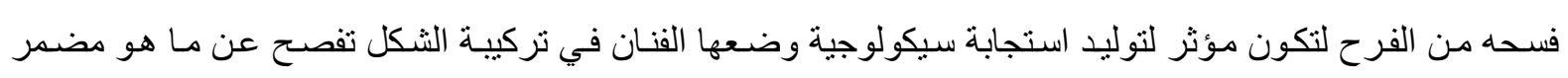
وظاهر في حساسية تلك التركيبة

شكل (ץ) صبيان يأكلان الرقي 9 هـ 9 1: نرى في هذا العمل ان خلفية اللوحة اتسمت بالبساطة والتسطيح مع خطوط تمثل

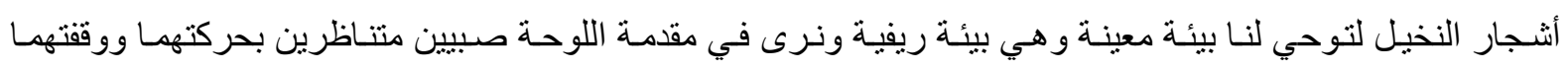

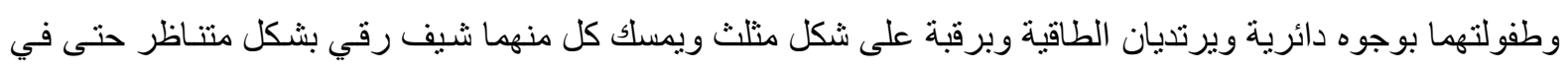

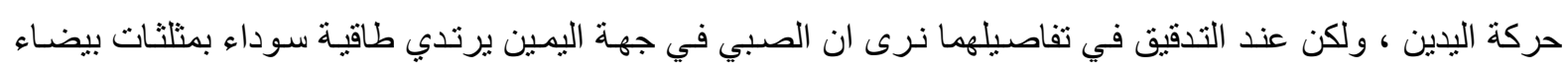

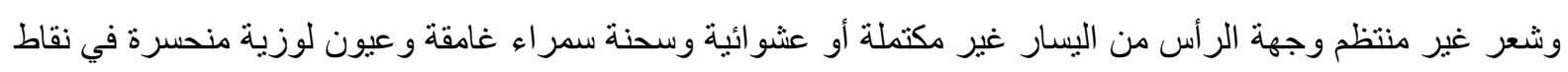

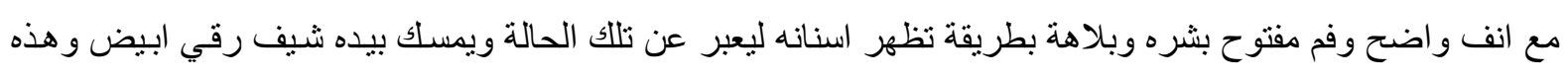

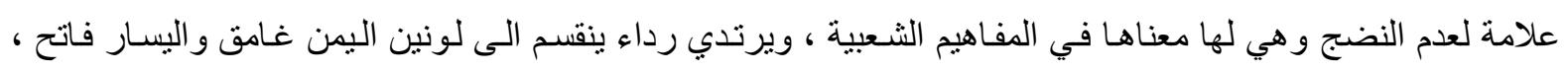

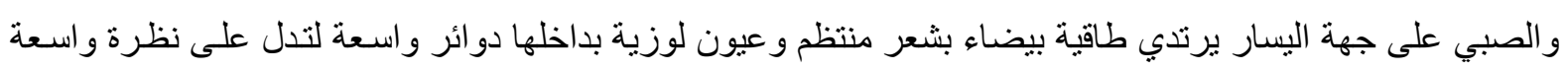

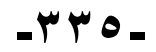


وبأنف واضح المعالم وفم مغلق ليدل الوجه على انتظام وكياسة مع شيف الرقي الاحمر ليكمل بدلالته مع تركيبة الوجـه

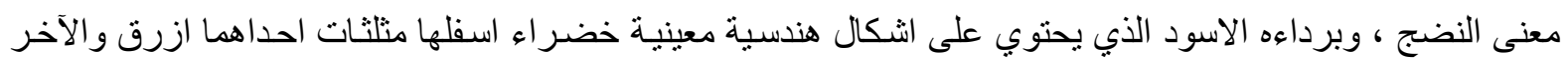

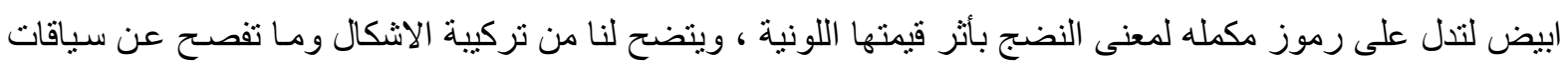

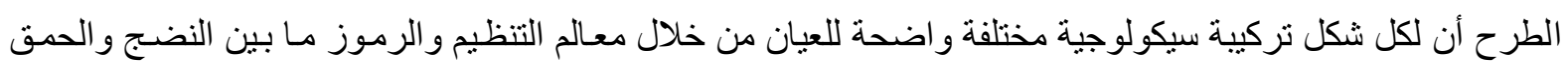
وما بين البلاهة و التوقد وهنا اختلفت التركيبة السيكولوجية لكل شكل بتفاصيلها الدقيقة ، ولكن تشابهت بعمومنيها ، كونهم

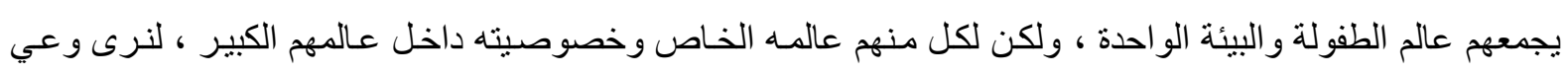

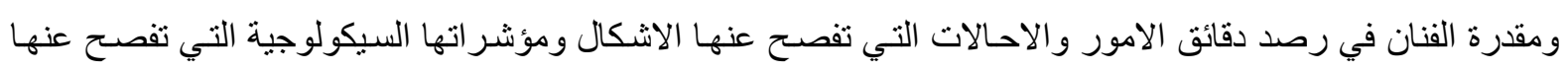

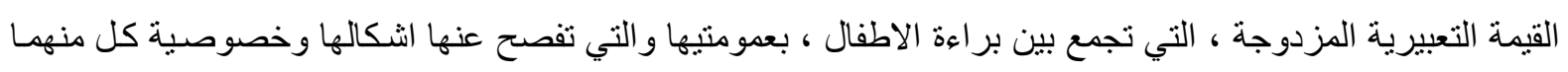

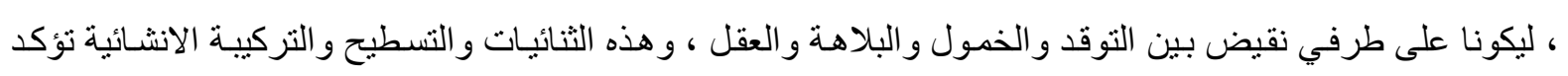

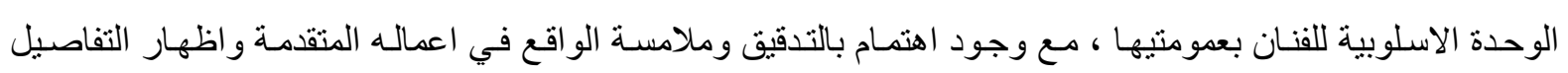

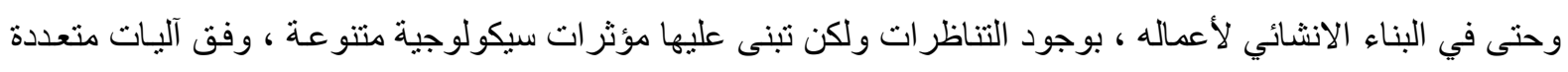

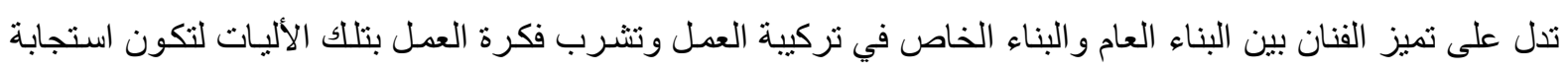
الاشكال عبر مؤثرات سيكولوجية لها أثرها الفاعل في و وعي المتلقي .

\section{|الفمل الرابع: نتائه البمث ومناقشتها}

1- توظيف الثنكل في فكرة العمل الفني وفق بنية اجتماعية وبيئية تتحول الى آلية تؤثر في تركيبة الثكل لحملها

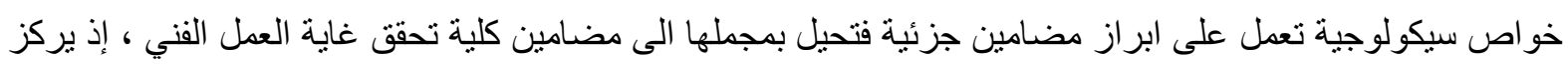

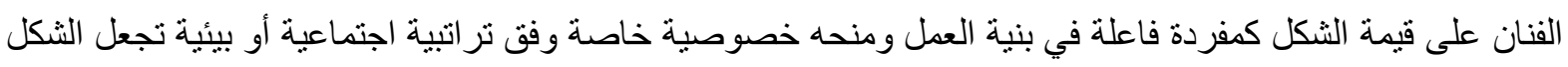
يتمظهر بخو اصها فتكون فكره العمل هي المثير الذي تبنى عليه التأثيرات السيكولوجية التي يبرزها الثنكل ومن ثم تكون تلاك التأثيرات هي التي تحقق مضمون العمل الفني بكليته .

r- منح الاشكال قيمة رمزية مزدوجة ليعبر الثكل عن خصوصيته بتفاعله مع خصوصيات الاشكال الأخرى ،

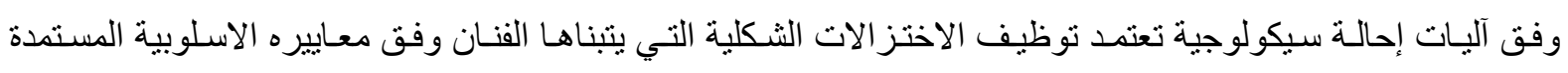
و المستلهمة من الفنون القديمة و الاسلامية كالتسطح والخطوط المحددة للأشكال لتختصر دلالاتها على أبراز تللك القيم الرمزية المزدوجة كأستجابات لمؤثرات ظاهرة أو مضمرة محققة دلالاتها السيكولوجية . r- تطويع التفاصيل الجزئية في الثكل لتحقيق المؤثرات السيكولوجية كأستجابات مثل الحزن و الفرح ومـا بينهما في ازدو اجية المعنى و المفهوم عبر التنوع في التوظيف لتلك التفاصيل ومـا تحمله من مؤثرات وبذللك المستوى من الاختز ال يحتاج الى قدرة إبداعية وفطنة مع وجود متغير لدى الفنان بتلك التفاصيل وكلمـا تقدمت الفترة الزمنية لأعمالـه

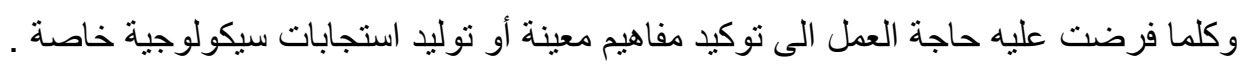
عـ - استخدام المفاهيم الاجتماعية المتعاقد عليها لتحقيق مضمون العمل الفني من خلال تنظيم شكلي يتو افق وتلك تلك

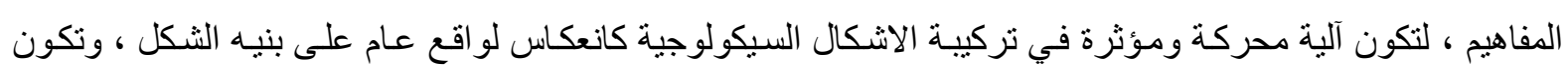

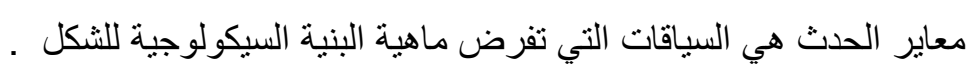
هـ خصوصية التعبير للنكل كمفردة فاعلة في العمل الفني من خلال حساسية ور هافة تركيبته وبنائيته التي تظهر بو اطن وأحاسيس الانسان حسب وضعه وتحقيق مؤثرات سيكولوجية واضحة تدل على دقة الملاحظة و التوظيف من قبل 
T- نوليد ثنائيات متضادة أو متكاملة باعتماد احالات جزئية في التركيبة السيكولوجية للأشكال ممـا يجعلها تقوم بتفعيل

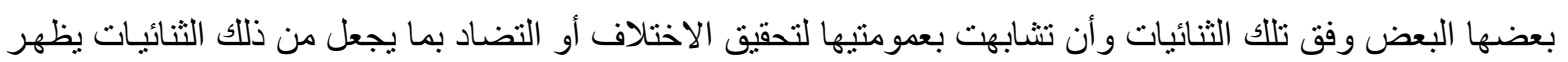
احدهما قيمة الاخر وهذا نوع أخر من التوظيف ونمط من الآليات التي استخدت في البناء السيكولوجي للنشكل وفق لهن معطيات المعنى العام .

\section{ب : الاستنتاجات :}

اـ يستنتج الباحث ان الثكل في العمل الفنـي يمكن ان يخضـع في بنائيته لمعـيير اجتماعيـة تفصـح عن مؤثرات سيكولوجية تكون فاعلة في توضيح وتحقيق تلك المعايير كمضامين بحققها البناء السيكولوجي للثنكل . r- تحقق القيمة السيكولوجية للثكل بدلالة التنظيم الثكلي الخاضع لمعايير وسياقات الحدث أو الفكرة الذي يمثل العمل . r- توظيف الاختز الات الثكلية وفق اساليب ومحددات فنيـة تسهم في تحقيق المؤثرات السيكولوجية من خلال التأكيد

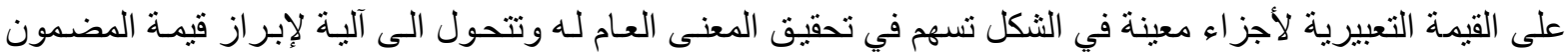
كون تلك الاجز اء تكون أكثر فاعلية في الاداء و التفاعل في بيئة العمل الفني .

\section{Hods|}

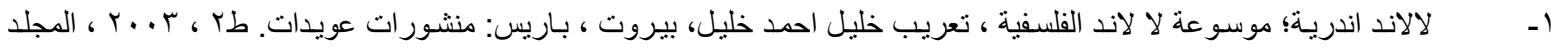

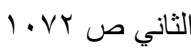

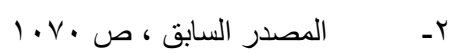

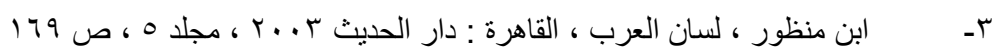

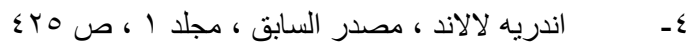

0ـ د. عبد الستار ابر اهيم ، الانسان و علم النفس الكويت : عالم المعرفة ، المجلس الوطني للثقافة والفنون والاداب ، 1910 ، ص 10

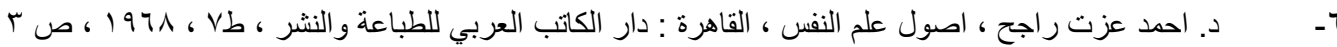

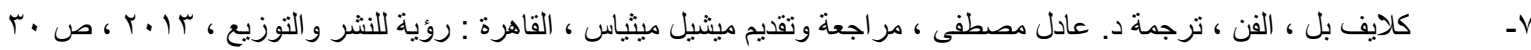

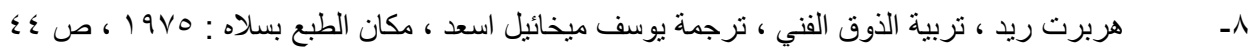

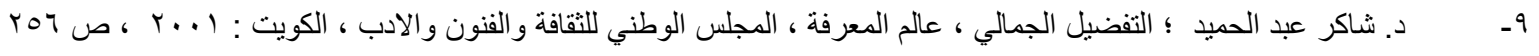

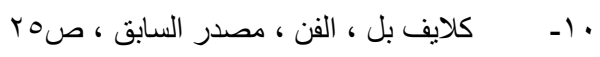

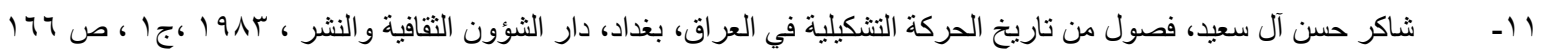

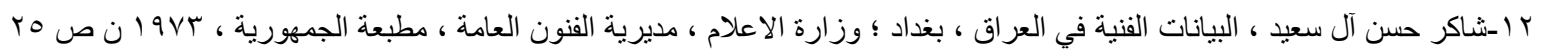

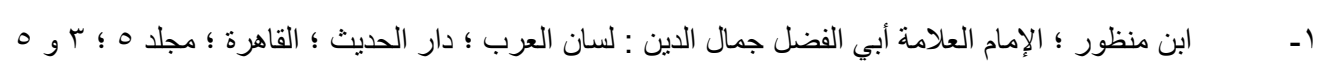
r- ابر اهيم ، عبد الستار : الانسان و علم النفس ، عالم المعرفة ، المجلس الوطني للثقافة والفنون والاداب ، الكويت ، 1910

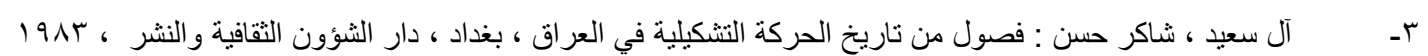

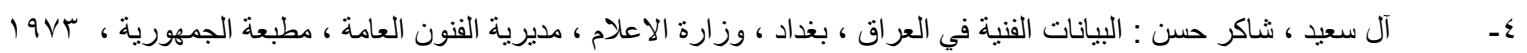

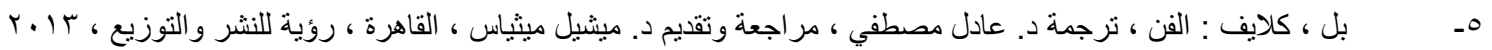

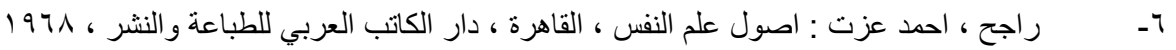

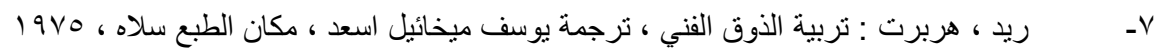

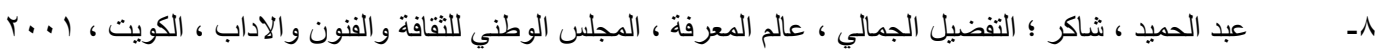


9- لالاند اندريه : موسو عة لالاند الفلسفية ، تعريب خليل احمد خليل ، منشورات عويدات ، بيروت ، باريس جr قائمة الإثكال

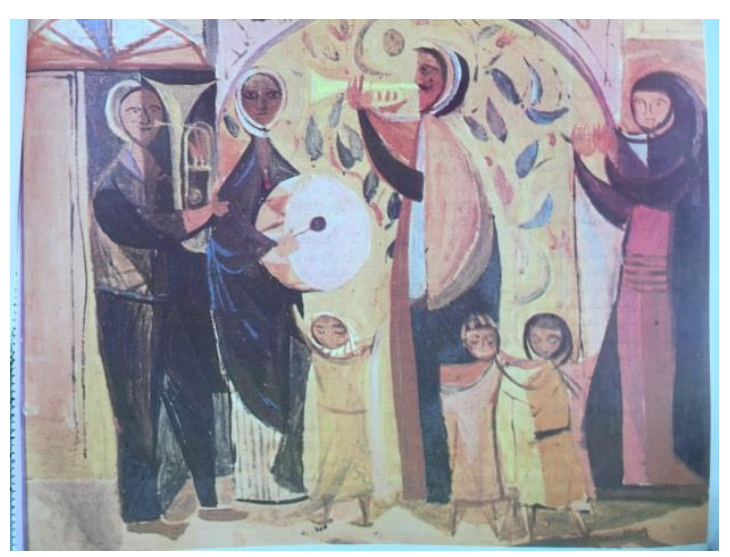

شكل رقم (r)

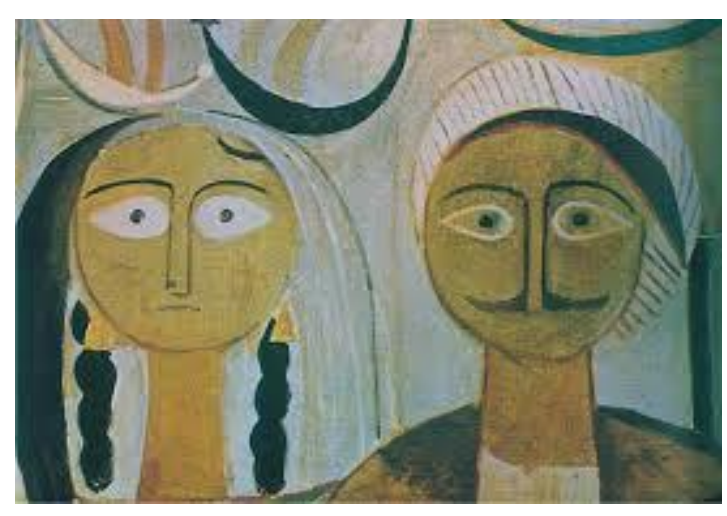

شكل رقم ( )

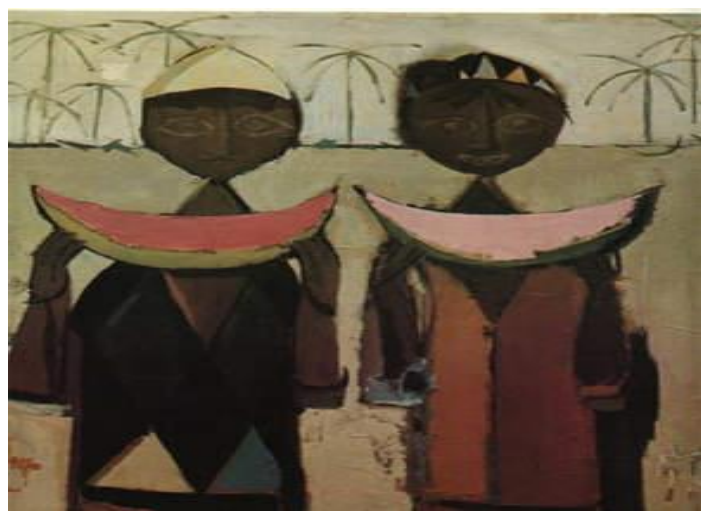

شكل رقم (r) 